\title{
Management of port industrial complex development: environmental and project dimensions
}

\author{
Vlada Orlova ${ }^{1 *}$, Igor Ilin $^{2}$ and Svetlana Shirokova ${ }^{2}$ \\ ${ }^{1}$ Southern Federal University, Taganrog, Nekrasovsky lane 44, 347900, Russian Federation \\ ${ }^{2}$ Peter the Great St.Petersburg Polytechnic University, Polytechnicheskaya, 29, St. Petersburg, \\ 195251, Russia
}

\begin{abstract}
Experience of the leading port industrial complexes indicated high socio-economic performance indicators. However, not every port becomes a basis for formation of a port industrial complex. In different countries, formation happens differently. According to the functional problems, Russian port industrial territories have a lack of development of managerial approaches to its formation and development. Overview of the development of Russian port industrial complexes shows that shortage of research on strategical management, including investment and institutional aspects, leads to an absence of methodological basis for engineering industrial port zones, as well as its strategical development. This requires detection of typical problems of the development of Russian and foreign port industrial complexes, definition of influencing factors, and systematization of managerial experience. During research process, methodology for system economic theory, which is best suited for a complicated territorial facility, was used. Such methodology considers interrelations among environmental, process, project, and object aspects. Namely, the problems of formation and development of port industrial complexes, as well as factors contributing to its growing potential, were identified and systematized in comparative order.
\end{abstract}

\section{Introduction}

Port industrial complexes (PIC) represent a foundation for development of different industries in cities and regions where they are situated. Thereby, they are widespread in the modern world. The biggest PIC are situated in Rotterdam, Hamburg, Antwerpen, Marcelle, Yokohama, New-York, Boston, Singapore and more of them in China.

The center of PIC development is a port. In the middle of 20th century, second generation ports were designed; they included strengthened integration processes and coordination of manufacturing planning with distribution. In 1980s, ports began to improve partnerships with companies working in ports and create industrial enterprises, not related with its core businesses. The creation of 3rd generation and then 4 th generation ports in 90 s was caused

${ }^{*}$ Corresponding author: vlada2266@gmail.com 
by development of large-scale container and intermodal transport. Combined with growing requirements of international trades, this allows to speak about possibility to form port industrial territory.

As the functions that were performed in the ports and adjacent territories were complicating, the formation of a complex territorial-branch facility, PIC, took place.

Despite a strong international trend, topic of industrial parks in the port territories is almost not developing. Almost near any seaport there is some industrial zone, but such an unsystematic set of separate and inefficiently used sites is very far from the modern approach to the organization of production sites [1]. Thereby, if there is a large number of developed sea ports and formed industrial complexes in the seaside territories, they are not always founding elements for regional economy.

Studies show that complexity of this object is due to a combination of many factors: industrial, corporate, logistical, infrastructural, institutional, biological, geographical etc., which has to be taken into account during the management process. Research of PIC, mainly represented by the work of industry (ecological, chemical-technological, marine) and territorial (geographical) nature. There are critically few systemic and complex works $[2,3]$.

In Russian research the most systematic in their studies are geographers, economogeographers, dealing with the issues of the multifaceted use of coastal territories, which become more acute in the context of globalization and hinder the integration of port and industrial areas into world economic processes. So, N.N. Torop believes that the water area and the adjacent territory in combination with other natural resources are a factor of regional development that determines the development potential of the "coastal integrated economic region" [4]. Which, in his opinion, unites natural-territorial complexes and autonomous enterprises on the basis of production links and common use of the territory and water area, as well as other resources.

Valev E.B. (geographer), while studying the role of coastal zones in the development of the European economy, determined the following characteristics of coastal production complexes:

- the activity of economic contacts, contributing to the expansion of the participation of countries in the international division of labor;

- high level of infrastructure facilities;

- the focus of their development are the port industrial centres [5].

Gogoberidze G.G. considers sea port and industrial complexes as an object of management and socio-economic development. He defines them as the combined capacity of the sectors and sectors of the economy that make up the maritime economic complex of the coastal territory that ensure sustainable economic development of maritime territories and maritime activities of the state [6].

It should be noted that most geography explorers understand the port-industrial territories (akin to PIC) as the production component within the port economy, for example, shipbuilding, ship repair, fish processing, which is part of the PIC.

The most systematic understanding of PIC, containing categorical features, was proposed by the geopolitician, geographer-economist Dergachev V.A.. He defined it as a systematically formed association of seaports, industrial enterprises, marine settlements, social and industrial infrastructure, which are located in the coastal zone of the seas because of the integrated use all types of resources, ensuring inter-branch and foreign economic relations, reducing transport costs, rational combination of territorial and sectoral administration [7].

Scientific and methodological support expands the prospects for adapting the institutional base necessary for the formation and management of the development of the PIC. The review of Russian works on the formation and development of port and industrial territories shows that this facility is not sufficiently explored at the present stage in terms of strategic management, including the institutional aspect of the activity. This explains the lack of a 
methodological basis for designing the PIC and developing strategies for its development, which makes this stage of work of more current interest.

Let's consider the problems of research presented in the works of foreign authors.

In the work devoted to the French port, the main attention is paid to the issues of functional complexity, evolution, diversity and mutual connectivity of industrial, agricultural and urban subsystems of the port city. The factors contributing to complex formation have been identified: the development of new energy technological routes, the emergence of metropolitan dynamics, the changing culture of business towards closer cooperation [8].

Another study is devoted to institutional changes in the ports of France. The port management model has recently changed as a result of the 2004 and 2008 reforms, which resulted in the decentralisation of management: the seventeen ports were changed from national to regional, the rights of its management were transferred to departments, but the role of the central government remained important. This led to an increase in the complexity of port management [9].

The subject of institutional conditions is developed in the study by Italian specialists who concluded that port management, carried out in a rigid institutional framework, without taking into account the impact of global problems at the local level, may lead to a systemic discrepancy between the tasks of the government level and requirements at the regional port level [10]. To solve this problem, the authors propose to adapt the control schemes taking into account local territorial contexts.

The focus of port research in Great Britain is the issue of the stability of port systems as subsystems of port cities with many stakeholders: government agencies, port operators, ship operators, importers, agents and logistics companies. The complexity of the ports leads to the complication of stakeholder interaction and actualizes the problem of barriers in communications [11].

Since the development of the port is inextricably linked with commercial activities, it is necessary to consider port development companies as port authorities [12]. In addition, there is a need for a joint open policy-making process by the city administration and the port, which takes into account the interests of private stakeholders and civil society, which increases the chances for the emergence of integrated strategies for port management work [13].

Thus, in foreign studies, a lot of attention is given to the development of ports as port industrial complexes, including aspects of managerial nature.

\section{Experimental section}

The socio-economic indicators of the major port industrial complexes in Europe (Rotterdam, Antwerp, Hamburg) demonstrate their ability to produce a synergistic effect as a result of the interaction of subsystems. PIC is an open and complex system that requires in the management of accounting the features of the seaside location and the influence factors: internal and external (at macro, meso- and micro levels), that is, in interrelation with the external environment and various social systems. In this way, for the successful management and solution of problems arising in the development of PIC, it is necessary to apply the appropriate research methodology, which in our opinion is a systematic approach, namely, system economic theory (SET).

Such an approach can solve the problem of imbalance and/or compatibility of territorial and sectoral approaches to the management of the national economy, which is important when developing a strategy for the development of local territorial-sectoral entities, which are PIC. SET is applied to the analysis of economic systems in a broad sense: it allows to consider the interaction of key subsystems of the national economy [14, 15]:

- economic science (environmental system);

- economic policy (process system); 
- management of the economy (project system);

- economic practice (object system).

The use of SET allows to systemise the factors of PIC development in four key blocks.

To identify the factors contributing to the development of PIC, it is necessary to structure information about them according to certain criteria, which, in the long term, will be important for the application of foreign experience in the development of Russian PICs.

Together, these subsystems constitute a complete complex that implements the full range of functions necessary for the stable functioning and development of the economy as a system (a combination of stability and variability, homogeneity and diversity). At the meta level, to which the considered economic system belongs - PIC, the economic system contains subsystems of all four types: object, process, project and environmental [14].

For the formation and effective functioning of PIC, a complex and balanced development of all four subsystems is necessary. However, the situation in the environmental subsystem of the meso-economic level, one of the main representatives of which in both domestic and foreign practice are PIC, the scientific sphere in the field of research of the processes of formation and development of PIC, demonstrates on the one hand the interdisciplinary nature of research, and on the other - unsystematic and lack of complexity [3]. This hinders the control process of the PIC (project subsystem). Therefore, at this stage of the study, we will consider the development of PIC in the framework of the elements of the SET: the environmental subsystem, which is the basis for the functioning of the project subsystem.

\subsection{The environmental aspect of the study}

The environmental system includes: socio-economic institutions, entrepreneurial climate, infrastructure [14]. Since the port is the center of PIC development, it is necessary to begin with an environmental aspect of the study - the institutional foundations of its functioning (ownership forms and types of port administration) that initiate the development of other elements of the environmental subsystem: infrastructure and investment climate.

As a result of the work of the United Nations Conference on Trade and Development "Legal Aspects of Ports Management" [16], three types of legal regime were identified in ports:

1. Ports under centralized control (under the control of state bodies).

2. Autonomous ports managed in a decentralized manner.

3. Ports of private management.

In any country, the state (parliament or administrative body) determines the legal regime of the ports and, consequently, the extent to which the port depends on the authorities. European ports of any form of ownership (state, municipal, state-municipal, private, mixed) are subordinated to the management company, often in the form of a joint-stock company.

The organizational structure of the Managing Companies of the ports of Rotterdam and Antwerp reflects the breadth of powers that they possess. It is noteworthy that in the structure of the Port of Rotterdam Authority (PRA) there are two divisions: container and logistics and industry and bulk cargoes, which report directly to the President and CEO of PRA. That is, the organisational structure of the PIC Management Company includes the functions of managing the port and industrial subsystem, which indicates the authority of PRA to manage such a system.

In the structure of managing the strategic development of the port of Antwerp, an indication of the development of the port and industrial complex is the presence of the functions of marketing, promotion and commercial relations in the sphere of business development in the Management Division.

The objectives of the PIC Rotterdam and PIC Antwerp (APA) Managing Companies are identical: increasing the competitiveness of the port as a logistics center and world-class 
industrial production, and ensuring a consistent steady increase in the value added of the territorial formation within which the PIC is located. Achieving this goal is provided by strategic and effective actions of PRA and APA managing companies to develop industrial zones and facilities for storage and reloading on the basis of concession agreements. At the same time, the management companies are responsible for the efficiency of land use and the compliance of new investments with the development strategies of the relevant PICs [17].

To improve competitiveness, the form of the Antwerp Port Authority was changed. In this way, until 1997 the port was managed by the mayor and the local council of the city of Antwerp, after that - the Management Company was established as an independent, municipal agency. This organizational and legal form gave the Management Company its own autonomous powers in the field of attracting labor resources, as well as in the creation of joint ventures. Since January 1st, 2016, the management company of the port of Antwerp has become an open joint stock company, which expands its powers, for example, in attracting commercial organisations to its territory for the development of industry $[18,19]$.

Within the environmental subsystem of the PIC, interaction of subsystems is observed, ensuring its development: revitalisation of institutional activity that stimulates the formation of a favourable investment climate, which, in turn, ensures the development of the PIC infrastructure. In this "cycle" of development with the help of the project subsystem, the object subsystem is activated, within the framework of which new logistics and production companies are being created [20]. For example, Rotterdam PIC has an effective management system for industrial enterprises operating on the basis of leases on its territory, which are already over 120 [18]. In accordance with the PIC development strategy, special measures are applied to attract new enterprises: introduction of preferential tariffs and periods of adaptation to local conditions.

Environmental subsystem of the Rotterdam's PIC creates the prerequisites for the formation and development of new industrial facilities. Thereby, PRA has the right of first choice, that is, any property located in the port area, but not owned by the Management Company, in case it has to be sold, should be first offered to PRA, which allows reasonable expansion of the PIC investment space and makes it available for the concession market. In making concession decisions regarding the territory removed from the port, the main criterion is the investment criterion. The management company approaches this strategically: first of all it concerns new investments and investments that bring long-term value added.

All applications of potential holders of concessions are carefully analysed. Making a decision to grant a concession, in addition to analysing the financial position of the company and the amount of planned investment, the objective and nature of the activity is taken into account to assess the degree of need for additional maritime transport, the prospects for direct and indirect employment, compliance with the adopted strategy and concession policy in order to maintain the adopted target Port operation facilities as an industrial PIC zone.

The organizational structure of the PIC Antwerp provides institutional tools and mechanisms for interaction between the Management Company and enterprises: the property management department, through its investment unit, offers a number of advisory services to companies that intend to invest within the PIC, projects to locate business (both inside and outside the port ), taxes, subsidies, fees and deductions. The task of this unit is the development of PIC in the framework of three strategic directions - port activities, industry (primarily chemical) and logistics. This task is decided on the basis of agreements with all relevant organisations.

In order to maximise the investment potential of the territory, the unit is authorised to act as the only contact person, which simplifies the search for available space for potential investors [21]. Thus, the effectiveness of the institutional environment can be judged by the development of the project PIC subsystem. 
In addition to PIC, located on the territory of the port (where both the port and the industrial zone are located), there are those which industrial zones are located outside the port. As in Antwerp and Hamburg (which appeared in the eleventh century and received additional large zones for industrial development in 2005) [1]. Thereby, the development of PIC abroad, took place in two directions: the expansion of the territory of the port and industrial territory within its borders or outside and the removal of the port from the restricting development of the city center to the periphery.

Given the specifics of the PIC, which industrial zone may be partially located in a significant distance and in a fragmented territory, it is necessary to improve the management process, mainly by the actions of the project subsystem within the spatiotemporal structuring of the PIC.

In Russia, regardless of the form of ownership (public, private, mixed), regulation of all seaports is carried out by the state in accordance with Art. 8 of the Federal Law "On Seaports" [22].

Regulation of activities in the seaports of Russia (as subsystems of PIC) is carried out by the state organisations of the Federal State Administration for Supervision of the Sea "Administration of Seaports" and FGUP "Rosmorport". The Federal Law "On Seaports" states that the purpose of their activities is to increase the competitiveness of seaports. However, this regulation does not apply to the financial and economic activities conducted by private companies on the territory of seaports, as well as issues of attracting investments and development of PIC. That is, there is a contradiction between the goals and objectives of the development of Russian ports and the rights of the institutions for port activity.

Despite problems stated above, which require solution, an analysis of the legal and regulatory framework regarding land and property relations in the seaports of Russia allows us to talk about positive opportunities for the formation and development of PIC. The main thing is that on the territory of Russian seaports, land plots can be in state and private ownership, which opens the possibility to develop the port infrastructure not only at the expense of federal funds [23]. In addition, it allows the state to initiate and participate in strategic projects jointly with commercial organisations operating in the port, and, consequently, to facilitate the formation of industrial enterprises on the territory of PIC.

\subsection{Project aspect}

The design system is a set of separate acts of control localised in space and time; the scope of transfer of organizational and economic mechanisms that lead to decisions taken before implementation (for example, building an edifice, mastering the production of a new type of product) $[14,15]$. The study of the project aspect of PIC activity is aimed at finding strategic guidelines for managing modern ports, as the basis for the formation of PIC. Under market conditions of uncertainty, only a professionally developed strategy is able to minimize the risks of economic activity [24].

Ensuring the competitiveness and integrated development of the port is possible if there is a precise strategy for the development of the port and territorial government structures that have sufficient authority to implement it [25]. In large European PIC (Rotterdam, Antwerp, Hamburg), management companies are creating a strategy for the development of the port, coordinating it with the appropriate committees of the city senate and federal structures.

Russian ports on the territory of which private companies operate are managed by state organisations of the FGBU "Administration of the seaport" and FGBU "Rosmorport", which are authorised to exercise state control (supervision) in accordance with the legislation of the Russian Federation [26]. That is, in fact, the AMP is not a subject of management of the port complex, since they do not perform administrative functions (goal-setting, planning, forecasting, organisation, motivation), except for control. 
Since different companies gravitate towards the ports (by the forms of ownership, in the spheres of their activity), the application of a service-oriented approach to the reengineering of business processes is actualized [27]. In addition, PIC are attractive for innovative companies, which has strategic importance for the development of complexe [28].

Stevedoring companies operating in Russian ports are independent private companies that do not coordinate their activities as port operators. In the presence of many stevedores there is a problem of a single purposeful management of the port complex as an object of state and regional interest. As a result, the tasks of coordination and integration of port activities are shifted to the shoulders of business or are resolved spontaneously and irregularly.

Successful functioning of PIC in Russia is observed within the framework of the Federal Target Programs (FTP), in this case, representatives of state institutions - AMP and Rosmorport, endowed with controlling functions, act as subjects of government. That is, the development of PIC occurs only within the framework of projects, and not on a systematic basis.

\section{Results}

In the course of work, on the basis of the system economic theory, the environmental and project aspects of the functioning of the port industrial complexes in Russia and abroad were compared in a comparative order.

\subsection{Environmental aspect}

An analysis of the institutional foundations of the functioning of foreign PICs has made it possible to formulate their specifics.

1. The mechanism of formation and functioning was worked out in market conditions, and in the course of globalization it was only improved, adapting to new conditions.

2. Development of foreign PIC, took place in two directions: expansion of the territory allocated to the port and industrial enterprises - on the one hand; and the removal of port facilities from the city center, which limits their development, to the periphery - on the other.

3. In foreign countries, state and municipal authorities approach the design and formation of new ports strategically - with the perspective of creating a PIC based on them.

4. Historically, the initiative to form a PIC may come from the port (that is, from the Port Managing Company) and from the industrial zone - from the relevant Management Company (state, municipal, private) industrial park or individual companies, if there are several parks. In the latter case, the company performs management functions not only of the industrial park (planning, construction of infrastructure, etc.), but also coordination of activities with the port, that is, participates in the activity of the design and process subsystems of the neoplasm.

As a result of the conducted studies, institutional and regulatory legal problems of the formation and functioning of PIC in Russia have been identified and systematized:

1. Inadequate features of economic activities of ports and regulatory framework.

2. The achievement of the objective of increasing the competitiveness of seaports (as PIC subsystems) specified in the Law on Seaports is complicated by the fact that activities in seaports are regulated by state organizations of the FGBU AMP and FGUP Rosmorport, which do not have the authority to conduct financial- economic activity of PIC.

3. The text of the Law "On Seaports in the Russian Federation" highlights provisions that are significant for the development prospects of PIC: articles regulating land and property relations, which opens the possibility to develop the port infrastructure not only at the expense of federal funds. 


\subsection{Project aspect}

In large European PIC (Rotterdam, Antwerp, Hamburg), management companies are developing a strategy for the development of the port, coordinating it with the profile committees of the city senate and federal structures.

In Russia, as a result of failures in economic science and politics, regarding the production subsystem of PIC, problems in the project subsystem (management of the economy) and the causes of their occurrence have been identified. In the presence of many stevedoring companies, there is no single purposeful management of the port complex as a subsystem of the PIC. Port administration subjects are the Administration of Seaports and Rosmorport, which have only control functions, except for goal-setting, planning, forecasting, organization and motivation. Successful functioning of PIC in Russia is observed within the framework of federal target programs, the implementation of which is controlled by the AMP and Rosmorport.

\section{Conclusions}

Based on the formulated results of the study, we can draw the following conclusion. For the system development of the port and the formation of the PIC in Russia, the adaptation of the institutional conditions for the functioning of ports and the existence of a single management structure is needed. The management structure should have the sufficient capabilities to collect up-to-date information on the activities of port operators, to develop management decisions within the framework of state, regional and city development strategies, control implementation of these decisions.

In our opinion, the application of systemic economic theory is able to create a system of coordinates in solving the existing problems. This work is the first step in this process, during which the environmental and project aspects of PIC activities were investigated. In the framework of the methodology used - SET, the key, in addition to these, are process and object (economic practice) aspects. Process is composed of economic and political processes, the totality of strategic decisions made in the sphere of economics. For a systematic study of Russian, in order to develop a concept for their balanced functioning of the PIC, further analysis of all aspects, in accordance with the SET, is necessary.

\section{References}

1. M. Furshchik, Informational and analytical magazine "Seaports", 4, 24-27 (2017)

2. V.Orlova, T. Alesinskaya, D. Arutyunova, Proceedings of the scientific works of the XX International Scientific and Practical Conference "System Analysis in Design and Management", 2, 104-108 (2016).

3. V. Orlova, T. Alesinskaya, D. Arutyunova, Proceedings of the II annual All-Russian scientific conference "Interdisciplinarity in Modern Social and Humanitarian Knowledge" 2, 243-252 (2017).

4. N.Torop, Primorsky integral economic region as an object of study of social and economic geography (2002)

5. E. Valev, Regional studies. 1, (2009)

6. G. Gogoberidze, Problems of modern economy. 2, 266-270 (2008)

7. V. Dergachev, Port industrial complexes: theory and practice offormation. (Kiev, 1988)

8. N.Mat, M. Lopez-Ferber, G. Junqua, J. Cerceau, J. Cleaner Production, 145, 159-171 (2017). 
9. J.Debrie, R.Lacoste, M.Magnan, Research in Transport. Business \& Management (2017).

10. F. Parola, C. Ferrari, G. Satta, E. Musso, A. Tei, Research in Transport. Business \& Management, (2017).

11. K. Achuthan, D. Shaw, A. Grainger, Technol. Forecast and Social Change (2016).

12. P. de Langen, L. van der Lugt. Research in Transport. Business \& Management, (2017).

13. P. Witte, B. Wiegmans, T. Spit, C. Braun Research in Transport. Business \& Management, 19, 97-105, (2016).

14. G. Kleiner, Issues of economics. 12, 107-123 (2015).

15. G. Kleiner Issues of economics. 1, 117-138 (2016).

16. Legal aspects of port management. Report by the UNCTAD secretariat. UNCTAD/SHIP/639. 11 February (1993) URL: unctad.org/en/docs/poshipd639.en.pdf

17. Official website of the port of Rotterdam: URL: https://www.portofrotterdam.com/

18. Official website of the port of Rotterdam: URL: http://www.portofantwerp.com/en/antwerp-port-authority

19. Russian shipping (industry portal): URL: http://www.russhipping.ru/ru/flag/news/?id=27264 от 26.01.2016.

20. T. Alesinskaya, D. Arutyunova, I. Ilin, S. Shirokova, Academy of strategic management journal is owned and published by Jordan Whitney Enterprises, Inc., PO Box 1032, Weaverville, NC 28787, USA. 16, Special Issue 1, 10-21 (2017)

21. Official website of the port of Antwerp: URL: http://www.portofantwerp.com/en/concession-policy

22. Federal Law of July 18, $2017 \mathrm{~N}$ 177-FZ "On Sea Ports in the RF from http://www.garant.ru/hotlaw/federal/1123826/

23. V. Orlova, R. Kachalov, XII International Scientific Conference NINR-2018 (Kazan, 2018).

24. V. Gloukhov, I. Ilin, V. Koposov, A. Levina, Asian Social Science. 10. № 24. 209-216 (2014)

25. The strategy of development of the sea port infrastructure of Russia until 2030, from http://www.rosmorport.ru/media/File/State-Private_Partnership/strategy_2030.pdf

26. URL: http://ivo.garant.ru/\#/document/12157006/paragraph/1073890170:0

27. I. Ilin, O. Iliashenko, A. Levina, Vision 2020: Innovation Management, Development Sustainability, and Competitive Economic Growth, 768-781 (2016)

28. V. Volkova, A. Loginova, S. Shirokova, E. Iakovleva, 19th IEEE, SCM 2017. Paper number 7519831, 515-517 (2017) 